\title{
Students' Interest in Undergraduate Fashion and Apparel Design Programs: The Case of Kenyan Universities
}

\author{
Rael Chepchumba Maiyo ${ }^{*}$, Susan Abong'o ${ }^{2}$ and David R. Tuigon' ${ }^{3}$ \\ ${ }^{1}$ Department of Family and Consumer Sciences, University of Eldoret, Kenya \\ ${ }^{2}$ Department of Art and Design, Maseno University, Kenya \\ ${ }^{3}$ School of Manufacturing and Textile Engineering, Moi University, Kenya
}

\begin{abstract}
In the recent past, the Asian countries have thrived in international apparel and textile trade, which is a great determinant of the success of a country's economy globally. One reason behind the success of their apparel and textile trade is their training programs in fashion and apparel design (FAD). Poor fashion quality in Kenya is attributed to incompetent fashion designers. Interest in the profession is a great asset to any training. This paper investigated into the interest of Kenyan university undergraduate fashion and apparel design students (UUFADSs) in university undergraduate fashion and apparel design programs (UUGFADPs) that they pursued. Information was drawn from a survey study among 99 UUFADSs and 32 university fashion and apparel design staff (UFADS) from five Kenyan universities. The study revealed that students' interests in fashion and apparel design (FAD) profession was high as reflected in the fact that majority of them said that they chose to study $F A D$, liked $F A D$, had jobs or businesses related to $F A D$, thought of self employment in FAD, planned to further their studies in FAD and were involved in extracurricular activities related to FAD. Students' lack of interest in FAD was caused by the learning activity/teaching method used in a lesson and too large classes, inadequate learning materials and equipment, gender bias in the teaching staff composition, among other factors.
\end{abstract}

Keywords: Students' Interests, University Undergraduate Programs, Fashion and Apparel Design, Teaching Methods

\section{Introduction}

Otiso [1] points out that, among the factors that contribute to the success of Asian textile production, are specialized training programs which ensure steady supply of middle and high-level management for their textile and apparel industry. It is further noted that sufficient numbers of high-skilled workers are needed to spearhead apparel design, equipment maintenance and production and marketing in the FTA industry. Such high-skilled workers are lacking in most African countries, Kenya included [1, 2].

According to Edwinsson \& Nilson [3], poor fashion quality in Kenya is attributed to unskilled and incompetent fashion designers. And to be able to effectively compete in the global fashion trade markets, they urge the Kenyan government to develop the apparel industry by enhancing skill training and thus have competent fashion designers.

According to this study, interest refers to a drive or an intrigue to do or like something. In this case it is what drives or motivate students to like FAD courses. Interests are also related to attitude. This paper determined information on the interests of Kenyan UUGFADSs and factors associated with their interest in UUGFADPs.

\subsection{Related Literature}

An educational program with, mission statement, learning objectives, outcomes, curriculum and program evaluation cannot be complete without students, who are the major target of an educational program and adequate student enrolment must be ensured for an effective program [4]. Muigai et al. [5] observe that, although careers were mainly determined by interests, abilities and potentials, in Kenya, most careers pursued by undergraduate students were dictated by the Joint Admissions Board (JAB). The courses pursued were therefore not popular among the students. The factors that greatly influenced the students' liking for a career were prestige associated with the profession and the remuneration offered by employers.

Edwinsson and Nilson's [3] study found that most design students at the University of Nairobi preferred to be industrial designers as a safer career due to a higher salary and ranking in the society. They also noted that students, especially male ones, were discouraged about joining the fashion design profession as it was regarded with a lower status. Muigai et al. [5] advocate for schools and/or faculties to have guidance and counselling departments with trained staff to guide students when making decisions regarding careers. In their opinion, the ministry of education should also train at least one guidance and counselling teacher for every secondary school who will expose students to different careers. Kurz [6] notes that fashion academic programs 
should not only consist of teaching facts, knowledge and skills but also attitude and guidelines towards the profession. Going by the fact that the above studies suggests students' interests and attitudes towards courses were crucial to an educational program, the current study established information on university fashion and apparel design (UFAD) students' interests in FAD and factors that were related to it.

\section{Materials And Methods}

This study was a descriptive survey research design to investigate on Kenyan UUFADSs' interest in learning of FAD. The study was carried out at Kenyatta, Maseno and Egerton Universities, University of Eldoret (UoE) and University of Eastern Africa-Baraton (UEAB) where the fashion and apparel design programs were offered.

Ninety nine (99) UUFADSs in the selected 5 university fashion and apparel design (UFAD) departments were selected purposively and were all able to respond to the questionnaires. The criteria for selecting the students was based on the level of study, hence the students were all the $3^{\text {rd }}$ and $4^{\text {th }}$ year students. These students had advanced in their training and had been exposed to the FA industry through industrial attachment. It is also at the undergraduate level that most of the practical skills in fashion/apparel design are imparted to students. It is therefore believed that the students were in a better position to give information regarding the UUGFADPs and the FA industry. All the 32 lecturers and technicians from the selected 5 UFAD departments were selected through saturation sampling. The total number of respondents was therefore 131.

Self-Administered Questionnaires which were both structured and unstructured, were distributed by the researcher to UUFADSs and UFADSs. The administration of the questionnaires was done manually and by electronic mail.

\subsection{Data Analysis and Presentation}

Qualitative and quantitative data deduced from the study were analyzed. Qualitative data was coded according to emerging patterns and then categorized and explained under themes. Quantitative data was statistically analyzed using the statistical package for social sciences (SPSS). Descriptive statistics, namely frequencies and percentages, were used to describe and summarize data. The results were presented in form of tables, plates and pie chart.

\subsection{UUFADSs' Interest in FAD}

\section{Results And Discussion}

Students' interest in FAD was determined by establishing: whether the students liked the UUGFADPs; areas liked in the program; whether they were involved in any business or job related to FAD at that time; where the students hoped to work after completing their studies; if they thought of self employment in FAD; students' plan to further studies in FAD and their involvement in extra curricula activities related to FAD. Table 1 presents the results on UUFADSs' interest in FAD.

Table 1: Students Interest in FAD

\begin{tabular}{lll}
\hline & Frequency & Percentage (\%) \\
\hline Like FAD & & \\
Yes & 91 & 92 \\
No & 8 & 8 \\
Total & $\mathbf{9 9}$ & $\mathbf{1 0 0}$ \\
Have job/business related to FAD & & \\
Yes & 57 & 58 \\
No & 42 & 42 \\
Total & $\mathbf{9 9}$ & $\mathbf{1 0 0}$ \\
\hline
\end{tabular}

Table 1 shows that 91(92\%) of the UUFADSs liked FAD. The areas liked by a majority were design, interior soft furnishing and fashion illustration. The least liked areas were common units which most of them were regarded as irrelevant like detailed textile science and courses involving "too much theory" such as history courses. Table 9 further shows that when the UUFADSs were asked whether they had any job or business related to FAD, 57 students (58\%) said yes while 42 students (42\%) never had.

Table 2 indicates the jobs /businesses related to FAD that were done by the UUFADSs.

Table 2: Jobs/Businesses Related to FAD that were done by UUFADSs

\begin{tabular}{lll}
\hline Have Job/Business Related to FAD & Frequency & Percentage (\%) \\
\hline Self-employment in apparel design & 28 & 49 \\
Interior soft furnishing & 15 & 26 \\
Employed in FAD related areas & 14 & 25 \\
Total & $\mathbf{5 7}$ & $\mathbf{1 0 0}$ \\
\hline
\end{tabular}


As presented in the table above, the jobs or businesses related to FAD included: self-employment in apparel design $(28,49 \%)$, including selling second hand clothing, hand knitting, lapidary, embroidery, fabric printing; interior soft furnishing $(15,26 \%)$ while 14 students $(25 \%)$ were usually employed in FAD related areas.

Table 3 presents the results on the jobs preferred by the UUFADSs upon completion of UUGFADPs.

Table 3: Jobs Preferred by UUFADSs upon Completion of UUGFAD Training

\begin{tabular}{lll}
\hline Jobs Preferred & Frequency & Percentage (\%) \\
\hline Fashion house & 49 & 50 \\
FAD training institutions & 15 & 15 \\
Interior Design firm & 19 & 19 \\
Other areas & 16 & 16 \\
Total & $\mathbf{9 9}$ & $\mathbf{1 0 0}$ \\
\hline
\end{tabular}

Forty nine students (50\%) wanted to work in a fashion house; 15 (15\%) in FAD training institutions; 19 students $(19 \%)$ with interior design firms and others $(16,16 \%)$ included fashion photography for magazines, firms such as deacons, KEBS, textile industries, self-employment and NGOs as shown in Table 3.

Table 4 shows the results on whether the UUFADSs thought of self employment in FAD related areas.

Table 4: Whether UUFADSs Thought of Self Employment (SE) in FAD Related Area

\begin{tabular}{lll}
\hline Thought of SE Related to FAD & Frequency & Percentage (\%) \\
\hline Yes & 97 & 98 \\
No & 2 & 2 \\
Total & $\mathbf{9 9}$ & $\mathbf{1 0 0}$
\end{tabular}

From the table, 97 (98\%) students thought of self employment (SE) in FAD at one point of their career lives while 2 students (2\%) had no thought of self-employment in FAD related area.

Table 5 presents the nature of self employment that the UUFADSs hoped to establish.

Table 5: Nature of Self Employment Hoped to be Established by UUFADSs

\begin{tabular}{lll}
\hline Nature of Employment & Frequency & Percentage (\%) \\
\hline Business on FAD & 65 & 67 \\
Business on Interior Design & 30 & 31 \\
Others (Fashion school, FAD trade) & 2 & 2 \\
Total & $\mathbf{9 7}$ & $\mathbf{1 0 0}$ \\
\hline
\end{tabular}

Sixty five $(67 \%)$ students wanted business in FAD related area; 30 students $(31 \%)$ in interior design while the rest included fashion school, import and export of apparel as indicated in Table 5.

Table 6 indicates the results on whether the UUFADSs had plans to further their studies in FAD and their involvement in FAD related areas.

Table 6: UUFADSs' Plan to Further Studies and their Involvement in FAD Related Area

\begin{tabular}{lll}
\hline & Frequency & Percentage (\%) \\
\hline Plan to Further Studies in FAD & 76 & 77 \\
Yes & 23 & 2 \\
No & $\mathbf{9 9}$ & $\mathbf{1 0 0}$ \\
Total & & \\
Involved in Extra Curricula Related to FAD & 62 & 63 \\
Yes & 37 & 37 \\
No & $\mathbf{9 9}$ & $\mathbf{1 0 0}$ \\
Total &
\end{tabular}

Seventy six students (77\%) had plans to further their studies in FAD, as shown in Table 14. The table also shows that 62 students $(63 \%)$ were involved in extracurricular activities related to FAD while 37 of them (37\%) were not. These activities included fashion shows (such as in class, church) fashion competition abroad, exhibitions and displays and fashion design clubs.

Reasons for further studies in FAD included: gaining more knowledge and skills by 59 (78\%) of the 76 students who planned to further their studies in the area; to get more job opportunities by 49 (65\%); to compete and prestige by $30(39 \%)$ and to become an expert in the area by $20(26 \%)$. Some UUFADSs felt that, by furthering their studies in FAD, they would have an opportunity to learn more on the areas that were not well taught in UUGFADPS such as CAD.

Reasons for not wanting to further studies in FAD included: further studies not necessary in fashion design since creativity is core in FAD (10, 43\%); it would be expensive to go for further studies $(10,65 \%)$; had learnt enough to enable self employment where most graduates of FAD landed $(7,30 \%)$ and that the local university institutions didn't have updated equipment for them to further study FAD at these universities (13, $57 \%)$. 
The students' interest in FAD profession is seen by the statistics in that the majority (79\%) of the UUFADSs said that they chose to study FAD, 92\% liked FAD, 58\% had jobs or businesses related to FAD, 98\% thought of self employment in FAD, 77\% planned to further their studies in FAD and 63\% were involved in extracurricular activities related to FAD and that they liked learning FAD. The implication, therefore, is that the students' interest in the UUGFADPs was high. This observation agrees with Kurz [6] who asserts that fashion academic programs should not only consist of teaching facts, knowledge and skills but also attitude and guidelines towards the profession. Muigai et al. [5] also emphasize that careers are mainly determined by interests, abilities and potentials. Referring to students' interest in the FAD profession, Kurz [6] further proposes that entry standards to the FAD profession could be set so that applicants to the profession show aptitude for being able to survive. The constituents' interest in the FAD profession was therefore a reflection of their positive attitude towards UUGFADPs and this can still be reinforced through setting more relevant entry standards upon admission to UUGFADPs.

Some of the UFADS however noted that sometimes the students were disinterested in FAD. During observation, such disinterest was noticed at some theory lessons. The implication was that the delivery of such theory lessons could influence the attitude of learners. Lack of interest by learners in FAD lessons could therefore be due to the large number of classes where the lecturer may not have been audible enough and teaching or learning methods that do not give learners a chance to focus on the learning content or the relevance of the course to FAD. This finding agrees with Pobywajlo [7] who notes that, in large lecture halls, students' attendances go unnoticed and their participation is minimized because in such settings, class discussions were rare and students' thinking was not provoked. Students' lack of interest in FAD was therefore caused by the learning activity/ teaching method used in a lesson and too large classes such that focusing on learners' concentration or participation in learning was had to determine.

Results from qualitative data indicate that the UUFADSs were least motivated by courses that involved much theory and those that they found to be unrelated to their area of study. This agree with Eskandari et al. [8] who note that, effort must involve making significant changes in the curriculum, transforming faculty instructional strategies in classrooms while producing experimental opportunities for students to attract students to the relevant profession. It is therefore worth noting that UUGFADPs should have its curriculum reviewed so that relevant courses are taught and mainly through practicals hence boost the UUFADSs' interest in the programs.

The fact that most students thought of being self-employed in FAD in future further implies that the students perceived the UUGFADPs as having a great opportunity in entrepreneurship hence had high interest in them. This observation agrees with Rao and Joshi [9] on the Indian fashion curriculum who suggest that a successful FAD curriculum should focus on creativity and preparing graduates to work as freelancers or selfemployed and the creation of small enterprises.

The finding on reasons for not wanting to pursue further studies in FAD by those UUFADSs who were not interested indicates that among the factors that discouraged the students, was that the local university and/or institutions did not have updated equipment for them to study FAD further. This observation agrees with Riechi [10] who notes that the quality of teaching of courses offered at the department could contribute to a negative perception hence poor image of the course in question. This finding implies that unavailability of relevant equipment for learning was one of the major demotivating factors in learning UUFADPs.

\subsection{Low Students' Interest and Competence}

In the view of UFADS, some students lacked interest: few showed interest as most of them gave an impression that they were being forced to learn. The UUFADSs and UFADS suggested motivation to students through more extracurricular activities such as fashion shows and clubs which would encourage them hence arouse interest in the program and give students an opportunity to compete. Other motivating factors proposed for UUGFADPs included hiring more male lectures to change the image of the course and ensure gender balance, change of the name(s) of the program where necessary, introduction of FAD related courses in high school as an option, revival of textile and apparel manufacturing industries, connecting students to attachment places that are relevant to FAD and those which will enrich them and networking students with industry to avoid prolonged search for jobs. In relation to students' experience from industrial attachment, it was suggested that the programs should be made to be more marketable and that FAD at degree level should be designed to appear different from that at lower levels such as at tertiary institutions. The UUFADSs also suggested that the UFAD departments could organize talks to students by fashion designers that are currently in the lead and find mentors who have succeeded in fashion industry to encourage the students. Class fashion competitions according to the UFADSs could also be organized and prizes awarded to winners.

The UFADS noted that some UUFADSs were not competent due to the fact that they did not have a background in the FAD area while others had a lot of knowledge; therefore bringing the students to the same level was not easy. The UFADS hence suggested that all UUFADSs, upon admission, should have some 
background/ entry knowledge in FAD, or a related area, which can be tested through practical test/oral interview.

Given that some of the UUFADSs were admitted to the UFAD departments through JAB, lack of interest in FAD by some UUFADSs could be due to the fact that in Kenya, most careers pursued by undergraduate students were dictated by the JAB and not necessarily by interests as noted by Muigai et al. [5]. It could also be as was observed by Edwinsson and Nilson's [3] that most design students at the University of Nairobi preferred to be industrial designers as a safer career due to a higher salary and ranking in the society and that male students particularly were discouraged about joining the fashion design profession as it was regarded with a lower status. This study agrees with Muigai et al. [5] who advocate for schools and/or faculties to have guidance and counselling departments with trained staff to guide students when making decisions regarding careers. The study further reiterate that courses such as FAD where students' interest is crucial should not be dictated by JAB but by the applicants' own choice.

\section{Conclusion And Recommendation}

The majority of UUFADSs had a background in FAD before joining the UUGFADPs due to the fact that some of them had either done related subjects in high school or they had done related courses. This boosted their interest in learning UFAD and they perceived the UFAD as an avenue for self-employment. The UUFADSs' interest in the FAD profession was high as reflected by the fact that the majority of the them said that they chose to study FAD, liked FAD, had jobs or businesses related to FAD, thought of self employment in FAD, planned to further their studies in FAD and were involved in extracurricular activities related to FAD. Students' lack of interest in FAD was caused by the learning activity/ teaching method used in a lesson and too large classes.

This paper recommends that in order to boost UUFADSs' interest in FAD they should be encouraged to participate in more extracurricular activities such as fashion shows and exhibitions, have class fashion competitions, mare male lecturers could be hired, the names of the degree programs can be changed to reflect what the program is all about, FAD related subjects be introduced at high school and have more mentorship programs/ talks from successful fashion designers. It is also more appropriate that the learning /teaching methods used should be relevant, classes should not be too large, upon admission, all the UUFADSS should have the same entry knowledge which can be tested and that schools / faculties should have trained staff who can guide students on their careers.

\section{References}

[1]. Otiso, K. M. (2004). Africa Growth and Opportunity Act and The Textile and Footwear Industry in Africa. In Mccormic, D., \& Rogerson, C. (Eds.). Clothing and Footwear in African Industrialization. South Africa: Africa Institute of South Africa.

[2]. Mager, D. (2005). China Textiles Curb a Little Relief for Africa. U.S.; New Era (Windhoek). Retrieved from: http://www.allAfrica.com Retrieved: June, $2^{\text {nd }} 2005$.

[3]. Edwinsson, L., \& Nilson, A. (2009). Dignity IV: Fashioning Kenya - A study of Kenya as a market for domestic fashion brands. The Swedish School of Textiles.

[4]. Coleman, J., \& Court, D. (1993). University Development in the Third World. Oxford: Pergamon Press.

[5]. Muigai, P., Kipruto, J., \& Korir, R. (2007). Perceived Relevance of undergraduate Degree Programs to students' Career Prospects: A case study of Moi University. The Educator: A Journal of the School of Education, Moi University. 1 (2), (i-xxvi, 1-270), 185198

[6]. Kurz, E. (2010). Analysis on Fashion Design Entrepreneurship: Challenges and Supporting Models. Unpublished Masters Thesis. The Swedish School of Textiles.

[7]. Pobywajlo, M. (2000). Changing Attitudes about General Education: Making Connections Through Writing Across the Curriculum. Manchester: UNH.

[8]. Eskandari, H., Sala-DIakanda, S., Furterer, S., Rabelo, K., Crumpton-Young, L., \& Williams, K. (2007). Enhancing the Undergraduate Industrial Engineering Curriculum - Defining Desired Characteristics and Emerging Topics. Education + Training, 49 (1), 45-55.

[9]. Rao, V., \& Joshi, H. G. (2011). Entrepreneurship Training in Apparel and Fashion Design Sector through Distance Mode: A Strategy for Facing the Challenge of Growing Unemployment in India. Retrieved from: http://www.wikieducator.org Retrieved: November, $22^{\text {nd }} 2012$.

[10]. Riechi, A. R. O. (2010). Discussion Paper No. 113/2010 on Demand for Regular Academic Programmes Offered in Kenya's Public Universities and their Relevance to the Labour Market. Nairobi, Kenya: Institute of Policy Analysis and Research (IPAR). 